\title{
Characterization of the maturational changes induced by a GnRH analogue in the rat ovarian follicle
}

\author{
N. Dekel, I. Sherizly, D. M. Phillips*, A. Nimrod $\dagger$, M. Zilberstein $\ddagger$ \\ and Z. Naor
}

Department of Hormone Research, The Weizmann Institute of Science, Rehovot 76100, Israel

\begin{abstract}
Summary. The GnRH analogue $\left[\mathrm{D}-\mathrm{Ser}(\mathrm{t}-\mathrm{Bu})^{6}\right]$ des-Gly ${ }^{10}-\mathrm{GnRH}-N$-ethylamide (GnRHa, $2 \mu \mathrm{g} / \mathrm{rat}$ ) or hCG (4 i.u./rat) was administered to hypophysectomized, PMSG-primed immature female rats. Oocyte maturation was initially detected by $2 \mathrm{~h}$ after GnRHa administration but the response to hCG was observed only after $4 \mathrm{~h}$. Initiation of GnRHa-induced ovulation also preceded the response to hCG by $2 \mathrm{~h}$. Maximal response to both these hormones was obtained at 10 and $14 \mathrm{~h}$ after hormone administration for oocyte maturation and ovulation respectively. The number of oocytes ovulated after GnRHa was significantly lower than that with hCG ( $29 \pm 4$ and $50 \pm 7$ per rat respectively; $P<0.05$ ). Expansion of the cumulus mass and secretion of mucoid material, which are characteristic responses to $\mathrm{LH}$, were also observed after GnRHa administration. However, while the action of $5 \mu \mathrm{g}$ ovine $\mathrm{LH} / \mathrm{ml}$ on the cumulus cells was mediated by cAMP, no accumulation of the nucleotide could be detected in follicles exposed to GnRHa $\left(10^{-7} \mathrm{M}\right)$. We conclude that even though GnRHa and LH/hCG seem to elicit similar responses in the ovarian follicle they differ in their kinetics, their efficiency and the mediator of their action.
\end{abstract}

\section{Introduction}

Various ovarian functions have been known to be triggered by gonadotrophin-releasing hormone (GnRH) indirectly via its stimulatory action on the pituitary to synthesize and secrete gonadotrophic hormones. However, direct, receptor-mediated, ovarian responses to GnRH have also been demonstrated (for review see Hsueh \& Jones, 1981). GnRH and its analogues can stimulate ovarian prostaglandin production (Clark, Thibier, Marsh \& LeMaire, 1980; Ekholm, Clark, Magnusson, Isaksson \& LeMaire, 1982; Zilberstein, Zakut, Eli \& Naor, 1984), trigger the oocyte to mature (Hillensjö \& LeMaire, 1980; Dekel, Sherizly, Tsafriri \& Naor, 1983; Erickson, Hofeditz \& Hsueh, 1983) and induce the follicle to ovulate (Corbin \& Bex, 1981; Ekholm, Hillensjö \& Isaksson, 1981; Dekel et al., 1983; Naor, Zilberstein, Zakut, Lindner \& Dekel, 1983). The same responses are elicited by luteinizing hormone (LH). Beyond the stage of hormone-receptor interaction there are some common mechanistic pathways shared by GnRH and LH in the ovary (Dekel et al., 1983). Specifically, we have shown that the phosphodiesterase inhibitor, methylisobutylxanthine, which is known to block LH action, effectively inhibits GnRH-induced oocyte maturation. We have also demonstrated that indomethacin, which inhibits prostaglandin formation, interferes with ovulation when GnRH or LH are used as inducers (Dekel et al., 1983).

*Present address: The Population Council, 1230 York Avenue, New York, N.Y., 10021, U.S.A.

†Present address: Biotechnology General (Israel) Ltd, Kiryat Weizmann, Rehovot, Israel.

†Present address: Department of Obstetrics and Gynecology, Sackler Faculty of Medicine, Tel Aviv University, The Edith Wolfson Hospital, Holon, Israel. 
The present study was undertaken to characterize the stimulatory responses of the ovary to a GnRH analogue in vivo as compared to $\mathrm{LH}$ action. The kinetics and maximal efficacy of a GnRH analogue and hCG in inducing oocyte maturation and ovulation were analysed. In addition, a possible effect of the analogue on the cells of the cumulus oophorus was studied, and the question whether cAMP mediates not only LH but also GnRH stimulatory action in the ovary was tested.

\section{Materials and Methods}

Hypophysectomy was performed by the transauricular approach with an 18-gauge needle on immature (25-day-old) Wistar-derived female rats (from our departmental colony) and was immediately followed by a subcutaneous injection of 15 i.u. PMSG (Gestyl: Organon, Oss, The Netherlands) in $0.1 \mathrm{ml} 0.9 \%(\mathrm{w} / \mathrm{v}) \mathrm{NaCl}$. An intravenous injection of $0.1 \mathrm{ml} 0.9 \%(\mathrm{w} / \mathrm{v}) \mathrm{NaCl}$ with or without the indicated dose of the GnRH analogue, $\left[\mathrm{D}-\mathrm{Ser}(\mathrm{t}-\mathrm{Bu})^{6}\right.$ ]des-Gly ${ }^{10}-\mathrm{GnRH}-\mathrm{N}-$ ethylamide (GnRHa) or a dose of 4 i.u. hCG/rat (Pregnyl: Organon) was given $48 \mathrm{~h}$ later. The rats were killed at the indicated time after administration of the hormones. Each animal was inspected for remnants of pituitary tissue, and those suspected of incomplete hypophysectomy were excluded.

To analyse the oocytes for maturation, the ovaries were removed and the oocytes from the large follicles ( $\sim 40$ follicles/rat) were recovered. Maturation, as indicated by the absence of the germinal vesicle (GV) in the individual oocytes, was analysed by Nomarski interference-contrast microscopy (Dekel, Lawrence, Gilula \& Beers, 1981). The results are expressed as the fraction of oocytes with GV breakdown (GVB) at each time point. Ovulation was analysed in rats treated as above but killed later. The oviducal ampullae were removed and examined for the presence of ovulated oocytes. The number of oocytes present in each oviduct was counted. The results are presented both as the total number of oocytes found in both oviducts of each individual rat and as the fraction of ovulating rats at each time point. Rats were considered as ovulating even when there was only one oocyte in the oviducts.

Some cumulus-oocyte complexes isolated from the oviducts of ovulating rats were prepared for scanning electron microscopy (SEM) as described by Dekel \& Phillips (1979). Briefly, the isolated complexes were rinsed in isotonic $\mathrm{NaCl}$ solution and fixed in $0.1 \mathrm{M}$-collidine-buffered $3 \%$ glutaraldehyde $(\mathrm{pH} 7.4)$ for $1 \mathrm{~h}$. The fixed complexes were placed on coverslips which had been presoaked in a $0.2 \%$ aqueous solution of poly-L-lysine $\mathrm{HBr}$ (type 1-B: Sigma, St Louis, MO, U.S.A.). Coverslips with attached cells were dehydrated through a graded series of acetone up to $100 \%$. Specimens were dried in a Sorval critical-point drying apparatus, coated with gold in an Edwards S150 sputter coater and examined in an ETEC autoscan.

Cyclic AMP determinations were performed on intact follicles isolated from immature PMSG-primed rats after incubation for the indicated times in L-15 (Leibovitz) tissue culture medium (Gibco, NY, U.S.A.) in the presence or absence of GnRHa $\left(10^{-7} \mathrm{M}\right)$ or ovine $\mathrm{LH}$ (NIH-LH-S24, $5 \mu \mathrm{g} / \mathrm{ml}$ ). The tissue was assayed by a competitive protein binding assay (Gilman, 1970) as modified by Lamprecht, Zor, Tsafriri \& Lindner (1973). Our assay detects between 5 and 50 pmol cAMP. The data represent accumulation as determined in samples of two follicles each.

Statistical analysis was performed by Student's $t$ tests.

\section{Results}

In the absence of further hormonal treatment, neither oocyte maturation nor ovulation occurred in hypophysectomized, PMSG-treated rats (Text-figs $1 \& 2$ ). However, the injection of GnRHa $(2 \mu \mathrm{g} / \mathrm{rat})$ or hCG (4 i.u./rat) $48 \mathrm{~h}$ after PMSG administration stimulated maturation of the oocytes as well as their release from the ovary. Mature oocytes were initially detected in the ovaries of the GnRHa-treated rats at $2 \mathrm{~h}$ after administration of the hormone while response to $\mathrm{hCG}$ was 


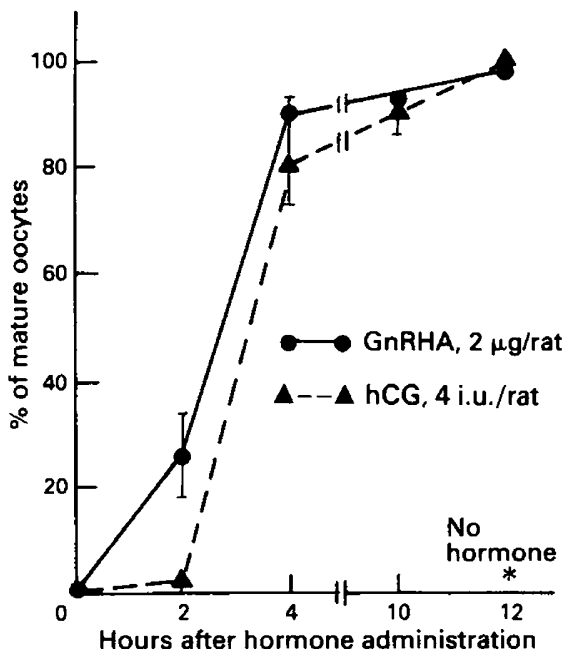

Text-fig. 1. Time-course of GnRHa- and hCG-induced oocyte maturation in hypophysectomized, PMSG-primed immature rats. At least 6 rats were examined at each time point. The fraction of mature oocytes was calculated for each individual rat and the results are presented as means \pm s.e.m.

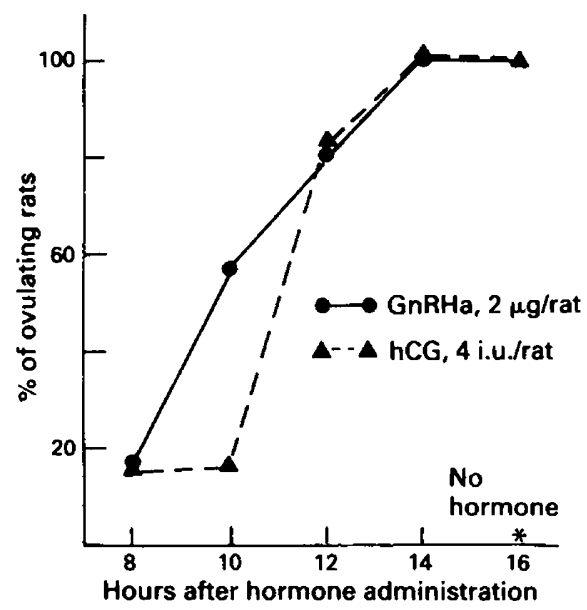

Text-fig. 2. Time-course of GnRHa- and hCG-induced ovulation in hypophysectomized, PMSG-primed immature rats. At least 6 rats were analysed for ovulation at each time point and the results are presented as the fraction of rats that ovulated of the total examined.

observed after $4 \mathrm{~h}$ (Text-fig. 1). Full response to both hormones was observed at $10 \mathrm{~h}$ (Text-fig. 1). While over $50 \%$ of the GnRHa-treated rats ovulated by $10 \mathrm{~h}$ after administration of the hormone, no ovulations were detected at this time in response to hCG (Text-fig. 2). In spite of the delay in the initiation time in hCG-induced ovulation, full ovulatory response to both these hormones was obtained by $14 \mathrm{~h}$ after their administration (Text-fig. 2).

A clear difference in efficiency of GnRHa and hCG was demonstrated by the number of oocytes induced to ovulate by each of these hormones (Text-fig. 3). While the maximal number of ovulated oocytes after hCG treatment was $50 \pm 7$ (mean \pm s.e.m.) per rat $(\mathrm{N}=8)$, only $29 \pm 4(\mathrm{~N}=13$ ) oocytes were released in response to GnRHa treatment $(P<0.05)$. A higher dose of GnRHa $(4 \mu \mathrm{g}$ per rat) did not increase the number of ovulated ova $(22 \pm 5 \cdot 3, \mathrm{~N}=7)$. 


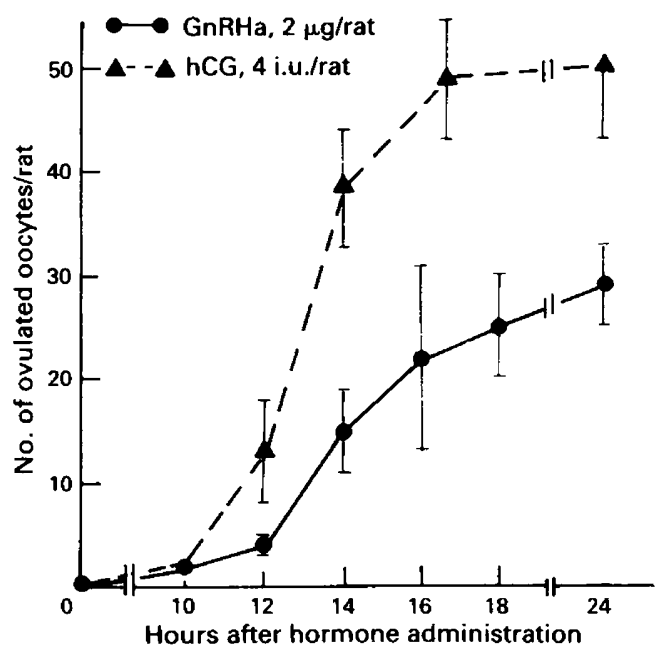

Text-fig. 3. Time-course of the ovulatory response to GnRHa and hCG in individual hypophysectomized, PMSG-primed immature rats. At least 6 rats were examined for each time point and the results are presented as the means \pm s.e.m. of the total number of oocytes present in both oviducts of each rat examined.

The oocyte and the cells of the follicular wall were apparently not the only follicular components affected by GnRHa. Like LH (Dekel \& Phillips, 1979), GnRHa induced expansion of the compact organization of the cumulus oophorus and stimulated the individual cells to change in morphology. GnRHa-treated cells were devoid of the long microvilli that characterized untreated cells (Pl. 1, Figs 1 \& 2), displaying large number of blebs on their surfaces (Pl. 1, Figs 3 \& 4). In addition, like LH, GnRHa-treated cumulus cells were stimulated to secrete a mucoid material that completely coated the cumulus masses (Pl. 1, Figs 3-6). These morphological changes were observed in all the postovulatory cumuli recovered from oviducts of GnRHa-treated rats. However, while LH action on the ovarian follicles was mediated by cAMP, no accumulation of this nucleotide could be detected in the follicular cells after exposure to GnRHa (Text-fig. 4).

\section{Discussion}

Amongst a variety of ovarian functions, the production of mature fertilizable oocytes and their release to the site of fertilization are of major physiological significance. Oocyte maturation and ovulation are induced by the preovulatory surge of the gonadotrophic hormone LH (Ayalon,

\section{PLATE 1}

Figs 1 and 2. Compact, non-mucified preovulatory cumulus-oocyte complex (Fig. 1). The cumulus complex is characterized by closely apposed smooth cells, and the cumulus cells are characterized by long microvilli which are associated with neighbouring cells (Fig. 2). There is no accumulation of extracellular materials. Fig. 1, × 175; Fig. $2 \times 1250$.

Figs 3-6. Mucified postovulatory cumulus-oocyte complexes. Complexes were isolated from the oviducts of hypophysectomized PMSG-primed immature rats after injection of hCG (4 i.u./rat: Figs $3 \& 4)$ or GnRHa ( $2 \mu \mathrm{g} /$ rat: Figs $5 \& 6)$. The expanded complex is covered by extracellular material. The individual cells display blebs. No differences were observed between complexes of hCG- and GnRHa-treated animals. Figs $3 \& 5$, × 175; Figs $4 \& 6, \times 1250$. 
PLATE 1
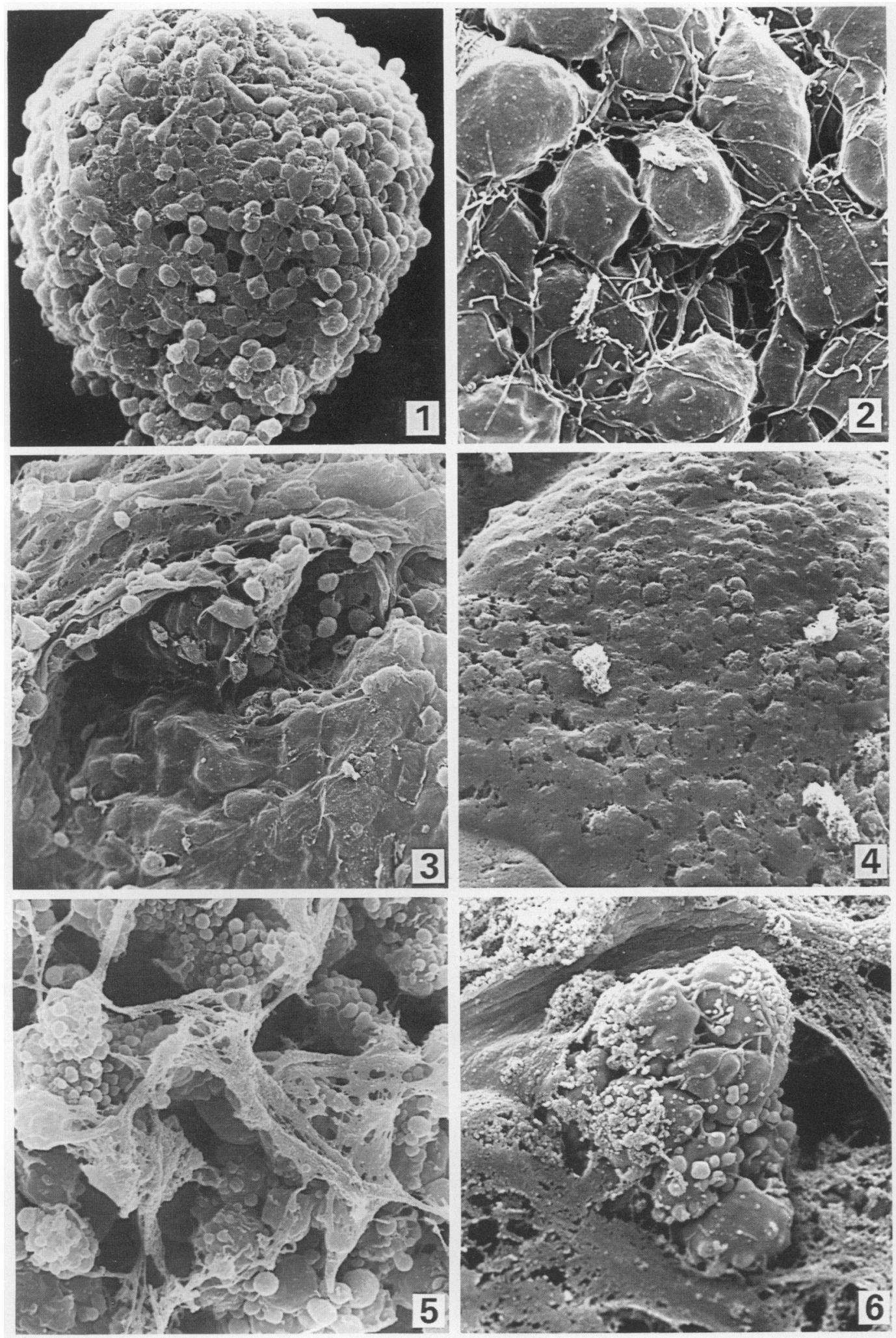


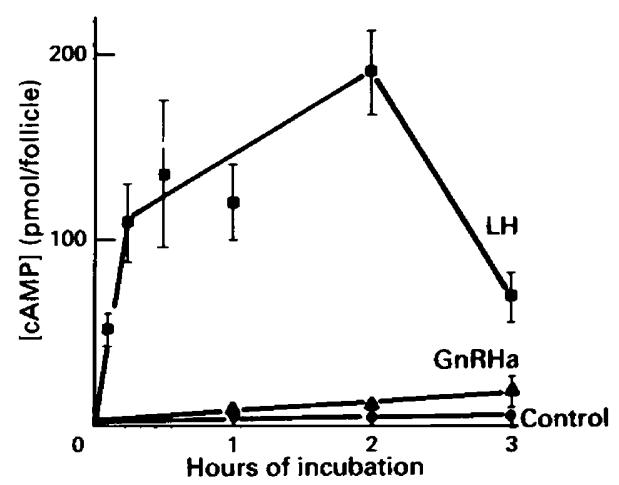

Text-fig. 4. Cyclic AMP accumulation by ovarian follicles in response to GnRHa or LH, Follicles were isolated from intact PMSG-primed immature rats and incubated in the presence or absence of GnRHa $\left(10^{-7} \mathrm{M}\right)$ or ovine $\mathrm{LH}(5 \mu \mathrm{g} / \mathrm{ml})$. Cyclic AMP was determined in samples of 2 follicles and the results are presented as means \pm s.e.m. of 5 replicates of 3 different experiments.

Tsafriri, Lindner, Cordova \& Harell, 1972). The finding that GnRH, which regulates the synthesis and release of $\mathrm{LH}$, can act directly on the ovary and induce these same responses was therefore unexpected. In the present study we have found differences in the characteristics of GnRHa and LH/hCG action on the ovarian follicle: (1) GnRHa elicits its action earlier; (2) GnRHa induces ovulation of a lower number of oocytes; and (3) the effect of GnRHa is not mediated by cAMP. In addition, we have shown that the oocyte and the follicular wall are not the only follicular compartments affected by GnRH analogues to exhibit responses characteristic of those induced by LH. The cells of the cumulus oophorus, which are the immediate neighbours of the oocyte in the follicle, also respond to a GnRH analogue in a way that is similar to their response to LH. After exposure to GnRHa the cumulus cells secrete a mucoid material which accumulates around them. Mucified cumulus-oocyte complexes isolated after GnRHa treatment cannot be distinguished morphologically from those isolated from an hCG-treated rat. Mucification of the cumulus cells is of physiological importance. The presence of the mucified mass of the cumulus cells is necessary to facilitate pick-up of the oocyte by the oviducal fimbria and transport of the oocyte to the site of fertilization (Mahi-Brown \& Yanagimachi, 1983). Moreover, with the help of acrosomal hyaluronidase, the spermatozoa of mice and rats can lyse the mucoid material that is present in the postovulatory cumulus and easily find their way to the mature oocyte (Austin, 1961).

The mediatory role of cAMP in the induction of oocyte maturation and cumulus mucification of LH has been clearly demonstrated (Dekel \& Kraicer, 1978; Dekel \& Sherizly, 1983). As cAMP is apparently not involved in GnRH action it is possible that this hormone triggers the cascade of events leading to oocyte maturation and cumulus mucification at a stage which is distal to the activation of the adenylate cyclase. This possibility could also explain the fact that the response to GnRH is manifested earlier than that to LH/hCG. Alternatively, since concentrations of prostaglandin (PG) E-2 do rise in response to GnRH (Clark et al., 1980; Zilberstein et al., 1984) and as both oocyte maturation and cumulus mucification can be induced by PGE-2 (Tsafriri, Lindner \& Zor, 1972; Phillips \& Dekel, 1982), it is possible that this messenger replaces cAMP in the mediation of GnRH action on the cumulus-oocyte complex. PGE-2 production in response to LH is delayed by $2 \mathrm{~h}$ as compared to the response to GnRH (Zilberstein et al., 1984). Moreover, since PGE-2 has been shown to be less effective than LH in the induction of oocyte maturation (Tsafriri et al., 1972), the lower number of oocytes per rat ovulating in response to GnRHa could be the result of a smaller pool of oocytes stimulated to mature by GnRHa via PGE-2. However, since indomethacin fails to inhibit GnRH-induced oocyte maturation (Ekholm et al., 1982; Dekel et al., 1983 ) it is doubtful whether PGE-2 is involved in this process. 
We conclude that GnRH and LH-hCG differ in their mechanism of action to induce oocyte maturation and cumulus mucification. However, as both these hormones stimulate PGE-2 formation (Clark et al., 1980; Zilberstein et al., 1984) and as ovulation is inhibited by indomethacin when GnRH or LH is used as the inducer, it seems that they do share some steps in the pathway to ovulation induction.

This work was carried out while D.M.P. was an Erna and Jakod Michael Visiting Professor at the Weizmann Institute of Science. We thank Dr H. Zakut for the interest taken in this study. This study was supported by the Minerva Foundation, Munich, West Germany.

\section{References}

Austin, C.R. (1961) The Mammalian Egg. Blackwell, Oxford.

Ayalon, D., Tsafriri, A., Lindner, H.R., Cordova, T. \& Harell, A. (1972) Serum gonadotrophin levels in prooestrous rats in relation to the resumption of meiosis by the oocytes. J. Reprod. Fert. 31, 51-58.

Clark, M.R., Thibier, C., Marsh, J.M. \& LeMaire, W.J. (I980) Stimulation of prostaglandin accumulation by luteinizing hormone-releasing hormone (LHRH) and LHRH analogs in rat granulosa cells in vitro. Endocrinology 107, 17-23.

Corbin, A. \& Bex, F.J. (1981) Luteinizing hormone releasing hormone agonists induce ovulation in hypophysectomised proestrous rats: direct ovarian effect. Life Sci. 29, 185-192.

Dekel, N. \& Kraicer, P.F. (1978) Induction in vitro of mucification of rat cumulus oophorus by gonadotropins and adenosine $3^{\prime}, 5^{\prime}$-monophosphate. Endocrinology 102, 1797-1802.

Dekel, N. \& Phillips, D.M. (1979) Maturation of the rat cumulus oophorus: a scanning electron microscopic study. Biol. Reprod. 21, 9-18.

Dekel, N. \& Sherizly, I. (1983) Induction of maturation in rat follicle-enclosed oocyte by forskolin. FEBS Lett. 151, 153-155.

Dekel, N., Lawrence, T.S., Gilula, N.B. \& Beers, W.H. (1981) Modulation of cell-to-cell communication in the cumulus-oocyte complex and the regulation of oocyte maturation by LH. Devl Biol. 86, 356-362.

Dekel, N., Sherizly, I., Tsafriri, A. \& Naor, Z. (1983) A comparative study of the mechanism of action of luteinising hormone and gonadotrophin releasing hormone analog on the ovary. Biol. Reprod. 28, 161-166.

Ekholm, C., Hillensjö, T. \& Isaksson, O. (1981) Gonadotropin-releasing hormone agonists stimulate oocyte meiosis and ovulation in hypophysectomized rats. Endocrinology 108, 2022-2024.

Ekholm, C., Clark, M.R., Magnusson, C., Isaksson, 0. \& LeMaire, W.J. (1982) Ovulation induced by a gonadotropin releasing hormone analog in hypophysectomized rats involves prostaglandins. Endocrinology 110, 288-290.

Erickson, G.F., Hofeditz, C. \& Hsueh, A.J.W. (1983) GnRH stimulates meiotic maturation in preantral follicles of hypophysectomised rats. In Factors Regulating Ovarian Function, pp. 257-261. Eds G. S. Greenwald \& P. F. Terranova. Raven Press, New York.
Gilman, A.G. (1970) A protein binding assay for adenosine 3',5'-cyclic monophosphate. Proc. natn. Acad. Sci. U.S.A. 67, 305-312.

Hillensjö, T. \& LeMaire, W.J. (1980) Gonadotropin releasing hormone agonists stimulate meiotic maturation of follicle-enclosed rat oocytes in vitro. Nature, Lond. 287, 145-146.

Hsueh, A.J.W. \& Jones, P.B.C. (1981) Extrapituitary action of gonadotrophin-releasing-hormone. Endocr. Rev. 2, 437-461.

Lamprecht, S.A., Zor, U., Tsafriri, A. \& Lindner, H.R. (1973) Action of prostaglandin $E_{2}$ and of luteinising hormone on ovarian adenylate cyclase, protein kinase and ornithine decarboxylase activity during postnatal development and maturity in the rat. $J$. Endocr. 57, 217-233.

Mahi-Brown, C.A. \& Yanagimachi, R. (1983) Parameters influencing ovum pick-up by oviductal fimbria in the golden hamster. Gamete Res. 8, 1-10.

Naor, Z., Zilberstein, M., Zakut, H., Lindner, H.R. \& Dekel, N (1983) Dissociation between the direct stimulatory and inhibitory effects of a gonadotropin releasing hormone analog on ovarian function. Molec. cell. Endocr. 31, 261-270.

Phillips, D.M. \& Dekel, N. (1982) Effect of gonadotropins and prostaglandin on cumulus mucification in culture of intact follicles. J. exp. Zool. 221, 275-282.

Tsafriri, A., Lindner, H.R. \& Zor, U. (1972) In vitro induction on meiotic division in follicle-enclosed rat oocytes by LH, cAMP and PGE-2. J. Reprod. Fert. 31, 39-50.

Zilberstein, M., Zakut, H., Eli, Y. \& Naor, Z. (1984) Regulation of prostaglandin $\mathbf{E}$, progesterone and cyclic AMP production in ovarian granulosa cells by luteinizing hormone and gonadotropin releasing hormone agonist: comparative studies. Endocrinology 114, 2374-2381. 